\title{
Determinants of acute mortality of Hippodamia convergens (Coleoptera: Coccinellidae) to ultra-low volume permethrin used for mosquito management
}

Robert KD Peterson, Collin J Preftakes, Jennifer L Bodin, Christopher R Brown, Alyssa M Piccolomini, Jerome J Schleier

There are relatively few experimental studies and risk assessments of the effects on nontarget insects from ultra-low-volume (ULV) insecticides used for management of adult mosquitoes. Therefore, we evaluated factors that may influence the ability of an insect to intercept the insecticide at the time of application by using Hippodamia convergens (Coleoptera: Coccinellidae) in field bioassay experiments in 2011 and 2015. Treatment factors included different distances, two cage heights (ground-level and $1.5 \mathrm{~m}$ above ground) to the point of the application, and covered vs. uncovered cage faces (2015 only). Insecticides used included a water-based formulation (Aqua-Reslin ${ }^{\circledR}$ ) and an oil-based formulation (Permanone ${ }^{\circledR}$ 30-30) of permethrin. Cage height was highly significant both years, with much less acute (i.e., short-term exposure) mortality at ground-level compared with $1.5 \mathrm{~m}$. In 2011, acute mortality was less at ground-level (mean $=3.2 \%$, median $=0 \%$ ) compared to $1.5 \mathrm{~m}$ (mean $=85.2 \%$, median $=100 \%$ ). Cage type also was highly significant, with less mortality in covered cages compared to uncovered cages. Mortality by cage height and cage type was as follows: ground level, covered cage (mean $=2.8 \%$, median $=0.1 \%)$; ground level, uncovered cage (mean $=41.9 \%$, median $=9.6 \%) ; 1.5 \mathrm{~m}$, covered cage $($ mean $=6.8 \%$, median $=0 \%) ; 1.5 \mathrm{~m}$, uncovered cage $($ mean $=83.7 \%$, median $=100 \%)$. Results suggest that acute mortality to non-target insects may vary considerably based on their height and their ability to directly intercept the insecticide as the aerosol passes through the area being sprayed. 
1 Determinants of Acute Mortality of Hippodamia convergens (Coleoptera: Coccinellidae) to

\section{Ultra-Low Volume Permethrin used for Mosquito Management}

5 Robert K D Peterson*, Collin J Preftakes, Jennifer L Bodin, Christopher R Brown, Alyssa M

6 Piccolomini, and Jerome J Schleier III

7

8 Department of Land Resources and Environmental Sciences, Montana State University, 334

9 Leon Johnson Hall, Bozeman, Montana 59717, USA

10

11

12 * Corresponding author: Robert K. D. Peterson, Department of Land Resources and

13 Environmental Sciences, Montana State University, Bozeman, Montana, 59717-3120, 406-994-

14 7927; bpeterson@montana.edu 


\section{Abstract}

16 There are relatively few experimental studies and risk assessments of the effects on non-target

17 insects from ultra-low-volume (ULV) insecticides used for management of adult mosquitoes.

18 Therefore, we evaluated factors that may influence the ability of an insect to intercept the

19 insecticide at the time of application by using Hippodamia convergens (Coleoptera:

20 Coccinellidae) in field bioassay experiments in 2011 and 2015. Treatment factors included

21 different distances, two cage heights (ground-level and $1.5 \mathrm{~m}$ above ground) to the point of the

22 application, and covered vs. uncovered cage faces (2015 only). Insecticides used included a

23 water-based formulation (Aqua-Reslin $\left.{ }^{\circledR}\right)$ and an oil-based formulation (Permanone $\left.{ }^{\circledR} 30-30\right)$ of

24 permethrin. Cage height was highly significant both years, with much less acute (i.e., short-term

25 exposure) mortality at ground-level compared with $1.5 \mathrm{~m}$. In 2011, acute mortality was less at

26 ground-level $($ mean $=3.2 \%$, median $=0 \%)$ compared to $1.5 \mathrm{~m}($ mean $=85.2 \%$, median $=100 \%)$.

27 Cage type also was highly significant, with less mortality in covered cages compared to

28 uncovered cages. Mortality by cage height and cage type was as follows: ground level, covered

29 cage $($ mean $=2.8 \%$, median $=0.1 \%)$; ground level, uncovered cage $($ mean $=41.9 \%$, median $=$

$309.6 \%) ; 1.5 \mathrm{~m}$, covered cage $($ mean $=6.8 \%$, median $=0 \%) ; 1.5 \mathrm{~m}$, uncovered cage $($ mean $=$

$3183.7 \%$, median $=100 \%$ ). Results suggest that acute mortality to non-target insects may vary

32 considerably based on their height and their ability to directly intercept the insecticide as the

33 aerosol passes through the area being sprayed. 


\section{Introduction}

35

Within integrated pest management (IPM) programs, ultra-low volume (ULV) applications of insecticides in outdoor environments reduce populations of mosquitoes and most likely reduce the incidence of mosquito-vectored viruses in mosquitoes, non-human vertebrates, and humans, providing public health benefits to the treated areas through the prevention of disease (Carney et al. 2008; Elnaiem et al. 2008; Macedo et al. 2010; Ruktanonchai et al. 2014). Ultra-low volume application technology for mosquito management is characterized by releasing into the air extremely low rates of insecticide active ingredient (e.g., $3.92 \mathrm{~g} / \mathrm{ha}$ and volume of total product (e.g., $0.1 \mathrm{~L} / \mathrm{min}$ ) in very small droplets (e.g., 5 to $20 \mu \mathrm{m}$ ) to maximize aerial coverage and knock down and kill flying adult mosquitoes. With the increase in mosquito-borne pathogens such as West Nile virus (WNV), insecticides such as permethrin are being used more extensively for adult mosquito control (Davis et al. 2007; Schleier III et al. 2012). Consequently, public concern about insecticides has also increased, including concern about risk to non-target insects and other arthropods (Roche 2002; Thier 2001).

The technology of using ULV insecticides for mosquito management was developed to maximize aerial coverage and target flying adult mosquitoes at twilight and night and not to target insects on foliage and other landscape features (Lofgren et al. 1973; Mount 1998; Mount et al. 1996). However, other than many years of anecdotal observations of little impact on nontarget insects, there are relatively few experimental studies and risk assessments of this technology on these ecological receptors. This is especially the case for ground-applied ULV insecticides (Davis \& Peterson 2008; Schleier III \& Peterson 2010b; Tietze et al. 1996). Results from the few experimental studies that have been conducted are equivocal, suggesting significant acute exposure and mortality of specific non-target insect taxa abundance in some cases but not 
57 in others (Bargar 2012b; Boyce et al. 2007; Breidenbaugh \& de Szalay 2010; Jensen et al. 1999;

58 Kwan et al. 2009; Tietze et al. 1996; Zhong et al. 2010; Zhong et al. 2004). Furthermore, in

59 viewing ground-applied ULV insecticide applications as part of our previous research (Davis \&

60 Peterson 2008; Preftakes et al. 2011; Schleier III \& Peterson 2010a; Schleier III \& Peterson

61 2010b; Schleier III et al. 2012; Schleier et al. 2010) as well as part of regular mosquito

62 abatement program activities, we have noticed that the behavior of the insecticide aerosol cloud

63 may explain some differences in acute mortality of non-target insects that have been observed.

64 Therefore, given the intrinsic hazard to non-target insects from broad-spectrum ULV

65 insecticides and the equivocal results reported to date and from our observations, we evaluated

66 some factors, such as height, that may influence the ability of an insect to intercept the

67 insecticide at the time of application. To do this, we used the adult convergent lady beetle,

68 Hippodamia convergens Guérin-Méneville (Coleoptera: Coccinellidae), a beneficial, predaceous

69 insect (Bjørnson 2008).

70 Materials and Methods

71 Test insects

72 Adult $H$. convergens that were wild-collected from California were purchased from

73 Planet Natural Garden Supply (Bozeman, Montana) immediately before experiments were

74 conducted in 2011 and 2015. This species was chosen because it is one of the more common lady

75 beetles found throughout North America, its use in biological control has become a traditional

76 practice in rural and urban settings, it is easily and inexpensively obtained in large numbers, and

77 adults are hardy and relatively easy to manipulate.

78 The adults were kept in a terrarium in a $4^{\circ} \mathrm{C}$ refrigerator before testing. Equal numbers of

79 males and females were transferred the day of testing to bioassay cages similar to the Clarke 
80 cage design described by Fritz et al. (2010): concentric, friction-fit cardboard rings (15.24 cm

81 diameter $\times 3.81 \mathrm{~cm}$ deep) secured by T-310 tulle fabric to each face. Once in the cages, the

82 beetles were kept at room temperature (ca. $23{ }^{\circ} \mathrm{C}$ ) for approximately 4 hours so that there was

83 sufficient time for them to warm up before being taken to the field.

\section{$84 \underline{2011 \text { study }}$}

The field study was performed in August 2011 at or near dusk to coincide with the peak

86

87

88 activity period of the target pest, mosquitoes, as recommended by the World Health Organization (WHO 2003). Permethrin, ([3-phenoxyphenyl]methyl 3-[2,2-dichloroethenyl]-2,2dimethylcyclopropane carboxylate), was used in a water-based formulation (Aqua-Reslin ${ }^{\circledR}$ ) and an oil-based formulation (Permanone ${ }^{\circledR}$ 30-30). Formulations were applied as follows: three replications with Aqua-Reslin at $1 / 2$ maximum label rate (3.92 $\mathrm{g}$ a.i./ha), two replications with Aqua-Reslin at $1 / 4$ maximum label rate (1.96 $\mathrm{g}$ a.i./ha), two replications with Permanone 30-30 at $1 / 2$ maximum label rate (3.92 $\mathrm{g}$ a.i./ha), and two replications with Permanone 30-30 at 1/4 maximum label rate (1.96 g a.i./ha). Therefore, there were nine total applications. Application rates one-quarter and one-half of the maximum label rate of permethrin are commonly used and typically provide satisfactory mortality of adult female mosquitoes (Efird et al. 1991). Applications of oil- or water-based formulations and application rates were randomly chosen. Replications (see above) were performed over time within the same night (20 min between replications) as well as over different nights. Applications began no earlier than $1900 \mathrm{~h}$ between 17 August and 30 August 2011.

The field site, located near Bozeman, MT (45³8'47.09"N, $\left.111^{\circ} 24^{\prime} 8.18^{\prime \prime} \mathrm{W}\right)$ was a fallow wheat field with very little ground cover. Three T-shaped PVC stands, approximately 1.5-m tall, were placed at 40-, 60-, and 100-m from the spray line (Fig. 1). Each stand had two cages of $25 \pm$ 
$1031 \mathrm{H}$. convergens per cage: one cage suspended from the right arm of the stand $1.5 \mathrm{~m}$ above the

104 ground and one cage at ground-level (Fig. 1). A stand was placed 30-m upwind of the point of

105 spray with two control cages positioned the same as the test cages.

106 All spray applications were made 40-m upwind of the first stand of cages. Air

107 temperature, relative humidity, wind direction, and wind speed were measured during each spray

108 application with a Hobo Micro Station Data Logger (Onset Computer Corporation, Bourne, MA)

109 attached to 12-bit temperature and relative humidity sensors with a solar radiation shield and a

110 wind speed and direction smart sensor positioned $2.5 \mathrm{~m}$ above the ground. A rotating droplet

111 impinger (constructed by Cascade County Weed and Mosquito Control, Great Falls, MT) was

112 located $100 \mathrm{~m}$ from the spray line and positioned $1.5 \mathrm{~m}$ off the ground to sample the aerosol

113 cloud at that location and verify that the droplets moved through the entire study area.

A GUARDIAN ${ }^{\circledR} 95$ ES (Adapco, Sanford, FL) ULV truck-mounted spray system was

115 used to make all pesticide applications. The spray was initiated and continued for 45 seconds as

116 the truck drove approximately $16.1 \mathrm{~km} / \mathrm{hr}$ in a straight $200-\mathrm{m}$ line. After the ULV sprayer was

117 turned off, the aerosol cloud was given 10 minutes to move through the spray zone. The cages

118 were collected and the $H$. convergens were transferred to $946 \mathrm{ml}$ (1 quart) wide-mouth mason

119 jars to avoid any increased acute mortality from residual permethrin on the cages. Mortality

120 counts were conducted 12 hours after the application. Individuals that were unresponsive to

121 being probed or grasped by a pair of forceps were considered dead. Treatment factors were

122 formulation, application rate, distance from spray source (40, 60, and $100 \mathrm{~m})$, and cage height

123 (ground-level and $1.5 \mathrm{~m}$ ).

\section{$124 \underline{2015 \text { study }}$}


Based on results from the 2011 study, we made some adjustments to the experimental

126 and treatment design for additional research. Although the 2011 study was a simple field

127 bioassay with several treatment replications designed to reveal if there were differences in

128 mortality between individuals at ground-level compared to $1.5 \mathrm{~m}$, it became apparent with the

129 existing design that we could not attribute the height differences in acute mortality to differences

130 in insecticide droplet behavior or the insect's ability to intercept the droplets. Therefore, we

131 incorporated ground-level and 1.5-m high rotary slide impingers to quantify insecticide droplets

132 (Fig. 2). We also added a covered cage-front treatment factor to better understand the role of

133 objects interfering with the insect's ability to directly intercept the insecticide droplets.

134 Methods for the 2015 study were the same as the 2011 study, with the following

135 differences. Field experiments were performed in June and July 2015 at or near dusk.

136 Formulations were applied as follows: five replications with Aqua-Reslin and six replications

137 with Permanone 30-30 at one-half maximum label rate (3.92 g a.i./ha). Therefore, there were 11

138 total applications. Applications of oil- or water-based formulations were randomly selected. As

139 in 2011, replications (see above) were performed over time within the same night as well as over

140 different nights. Applications began no earlier than 1930 h between 30 June and 9 July 2015.

141 The field site, located at the MSU Bozeman Agricultural Research and Teaching Farm in

142 Bozeman, MT $\left(45^{\circ} 39^{\prime} 56.5^{\prime \prime} \mathrm{N}, 111^{\circ} 04^{\prime} 28.6^{\prime \prime} \mathrm{W}\right)$ was a recently cut grass hay pasture. The cutting

143 immediately before the study was performed ensured very little ground cover during the

144 experiments, which was similar to the 2011 study. Two I-shaped PVC stands, $1.5 \mathrm{~m}$ tall, were

145 placed at $20 \mathrm{~m}$ and $40 \mathrm{~m}$ from the spray line (Fig. 3). Based on 2011 results (see below) and

146 practical reasons, we eliminated the cage stands at $60 \mathrm{~m}$ and $100 \mathrm{~m}$ but added a cage stand at 20

$147 \mathrm{~m}$ to determine if beetles closer to the spray source would be more susceptible to acute mortality 
148 (Fig. 1). Each stand had four cages of $25 \pm 1 \mathrm{H}$. convergens per cage of equal ratios of males and

149 females: two cages suspended from the upper arm of the stand $1.5 \mathrm{~m}$ above the ground and two

150 cages suspended from the lower arm at ground-level. All cages were constructed with T-310

151 tulle fabric secured to each face of the cage. Half the cages (i.e., one each on the upper and lower

152 arms) were covered with plastic polyvinyl chloride wrap over the tulle on the face of the cage

153 that received the spray because of the wind direction (Fig. 4). Placement of the two cage types on

154 each arm of the stand was randomized. A stand was placed 30-m upwind of the point of spray

155 with four control cages positioned the same as the test cages.

156 Two rotating droplet impingers (Leading Edge Associates, Inc., Fletcher, NC) were

157 located at each stand, one at the height of each cage. Impingers rotated both Teflon- and

158 magnesium oxide-coated slides (for oil- and water-based formulations, respectively) at a speed

159 of $5.6 \mathrm{~m} / \mathrm{s}$. Slide dimensions were 75 X $25 \mathrm{~mm}$ and were positioned $18.4 \mathrm{~cm}$ apart from center to

160 center. The DropVision ${ }^{\circledR}$ measuring system (Leading Edge Associates, Inc., Fletcher, NC) was

161 used to obtain droplet data from slides. This system consists of a specialized compound

162 microscope, with a built-in imaging processor, to analyze droplets on slides while eliminating

163 background objects.

164 All spray applications were made 20-m upwind of the first stand of cages. The spray was

165 initiated and continued for 20 seconds as the truck drove $16.1 \mathrm{~km} / \mathrm{hr}$ in a straight $60-\mathrm{m}$ line. The

166 spray line was perpendicular to the wind direction at each spray. Because there was not a cage

167 stand at $60 \mathrm{~m}$ or $100 \mathrm{~m}$, the spray line was shorter in 2015 (ASAE 2009). Air temperature,

168 relative humidity, wind direction, and wind speed were measured during each spray application

169 with a Kestrel 4000 Weather \& Environmental Meter (Nielsen-Kellerman Company, Boothwyn, 
170 PA). Treatment factors included formulation, distance from spray source (20 and $40 \mathrm{~m})$, cage

171 position (1.5 $\mathrm{m}$ or ground-level), and cage type (covered front or uncovered front).

\section{Data analysis}

173 Acute mortality data were skewed strongly toward either $0 \%$ or $100 \%$, depending on

174 whether the individuals were at ground-level or 1.5-m high (2011 and 2015) or in covered or

175 uncovered cages (2015). Therefore, the variability did not meet assumptions of homogeneity

176 using the UNIVARIATE Procedure (SAS 9.3, SAS Institute, Inc., Cary, North Carolina, USA)

177 and the data could not be transformed to meet homogeneity. Therefore, the data could not be

178 statistically analyzed using parametric procedures. Consequently, the data were analyzed within

179 a contingency-table structure using Chi-square and Fisher's exact test $(\alpha=0.05)$ procedures

180 (Sokal \& Rohlf 1981) with the FREQ Procedure (SAS 9.3, SAS Institute, Inc., Cary, North

181 Carolina, USA). Logistic regression was used to examine significant effects $(\alpha=0.05)$ of droplet

182 density measured on the slides, volume median diameter (VMD) measured on the slides,

183 windspeed, temperature, relative humidity with the LOGISTIC Procedure (SAS 9.3, SAS

184 Institute, Inc., Cary, North Carolina, USA). The Wilcoxon rank sign test was used to determine if

185 there were differences in VMD and droplet density between distance and height using $\mathrm{R}$

186 statistical package version 3.2.0 (R Foundation for Statistical Computing, Vienna, Austria)

187 because neither droplet density nor VMD were normally distributed.

188 In 2011, it was not necessary to correct treatment mortality with control mortality using

189 Abbott's formula because there was no mortality in the control treatments (Abbott 1925). In

1902015 , treatment mortality needed to be corrected for five of the 11 applications. However,

191 control mortality did not exceed $11 \%$.

\section{Results}




\section{Mortality}

194

195

196

197

198

199

200

201

202

203

204

205

206

207

208

209

210

211

212

213

214

215

2011

The rotary impinger at $100 \mathrm{~m}$ collected insecticide droplets during each spray application (mean droplet density $=0.94 \pm 0.08$ droplets $/ \mathrm{mm}^{2} ;$ mean $\left.\mathrm{VMD}=15.7 \pm 5.73 \mu \mathrm{m}\right)$, indicating

that the aerosol passed through the 40-, 60-, and 100-m sample distances. There were significant formulation $\left(\mathrm{df}=1 ; \mathrm{X}^{2}=8.08 ; \mathrm{P}<0.005\right)$ and distance $\left(\mathrm{df}=2 ; \mathrm{X}^{2}=9.86 ; \mathrm{P}<0.007\right)$ effects on mortality. The acute mortality of $H$. convergens exposed to Aqua-Reslin and Permanone 30-30 was $47.6 \%$ and $39.8 \%$, respectively. The mortality of individuals at 40,60 , and $100 \mathrm{~m}$ was $47.9 \%, 46.6 \%$, and $38.2 \%$, respectively; mortality was significantly lower at $100 \mathrm{~m}$ than 40 or 60 $\mathrm{m}$. This is not surprising because $100 \mathrm{~m}$ is at the far end of the effective swath width for groundbased ULV applications of insecticides for mosquito control.

Cage height was highly significant $\left(\mathrm{df}=1 ; \mathrm{X}^{2}=897.29 ; \mathrm{P}<0.0001\right)$. Acute mortality was significantly lower at ground level $($ mean $=3.2 \%$, median $=0 \%)$ compared to $1.5 \mathrm{~m}(\mathrm{mean}=$ $85.2 \%$, median $=100 \%)($ Fig. 5$)$. Therefore, mortality was not independent of height. The logistic regression revealed significant effects of wind speed $\left(\mathrm{df}=1 ; \mathrm{X}^{2}=7.28 ; \mathrm{P}=0.007\right)$ on overall mortality, but the interaction of cage height-by-wind speed was not statistically significant.

\section{5}

Unlike the 2011 study, there were no significant formulation $\left(\mathrm{df}=1 ; \mathrm{X}^{2}=1.18 ; \mathrm{P}=0.28\right)$ or distance $\left(\mathrm{df}=1 ; \mathrm{X}^{2}=2.65 ; \mathrm{P}=0.1\right)$ effects on acute mortality. Formulation was not significant possibly because more replications at one rate were conducted in 2015 compared to 2011. Distance was not significant most likely because $20-\mathrm{m}$ and 40-m distances were relatively close and we did not have a 100-m distance in 2015. 
Like the 2011 study, cage height was highly significant $\left(\mathrm{df}=1 ; \mathrm{X}^{2}=130.12 ; \mathrm{P}<0.0001\right)$,

217 with acute mortality lower at ground-level compared to $1.5 \mathrm{~m}$ (Fig. 6). Cage type was highly

218 significant $\left(\mathrm{df}=1 ; \mathrm{X}^{2}=840.2 ; \mathrm{P}<0.0001\right)$, with mortality lower in covered cages compared to

219 uncovered cages (Fig. 6). Mortality by cage position and cage type was as follows: ground level, 220 covered cage $($ mean $=2.8 \%$, median $=0.1 \%)$; ground level, uncovered cage $($ mean $=41.9 \%$, 221 median $=9.6 \%) ; 1.5 \mathrm{~m}$, covered cage $($ mean $=6.8 \%$, median $=0 \%) ; 1.5 \mathrm{~m}$, uncovered cage $222($ mean $=83.7 \%$, median $=100 \%)$.

223 The logistic regression revealed significant effects of wind speed $\left(\mathrm{df}=1 ; \mathrm{X}^{2}=9.18 ; \mathrm{P}=\right.$ $2240.002)$, relative humidity $\left(\mathrm{df}=1 ; \mathrm{X}^{2}=7.31 ; \mathrm{P}=0.007\right)$, and temperature $\left(\mathrm{df}=1 ; \mathrm{X}^{2}=8.79 ; \mathrm{P}=\right.$ 2250.003 ) on acute mortality in the uncovered cages at ground-level, but not at $1.5 \mathrm{~m}$. This suggests 226 that mortality of individuals in the cages at ground-level was more dependent on these 227 environmental factors than individuals in the cages at $1.5 \mathrm{~m}$.

Surprisingly, there were no significant differences in droplet density and VMD between ground-level and $1.5 \mathrm{~m}$. Therefore, reductions in mortality of individuals at ground-level cannot 230 be explained simply by lower insecticide droplet densities or changes in VMD. There was, 231 however, a significant difference in droplet density between the 20- and 40-m distances 232 (Wilcoxon rank sign test, $\mathrm{W}=1264, \mathrm{P}=0.013$ ) (Table 1).

\section{Weather}

The average $( \pm \mathrm{SD})$ temperature and wind speed during the applications in 2011 were

$31.2 \pm 1.7^{\circ} \mathrm{C}$ and $14.5 \pm 4.3 \mathrm{~km} / \mathrm{hr}$. The 2011 data for relative humidity could not be used because the sensor was not functioning properly during the applications. The average $( \pm$ SD)

237 temperature, relative humidity, and wind speed during the applications in 2015 were $26.2 \pm 4.2$ ${ }^{\circ} \mathrm{C}, 38.7 \pm 7.6 \%$, and $7.7 \pm 3.4 \mathrm{~km} / \mathrm{hr}$. 


\section{Discussion}

To our knowledge, this is the first study to show that acute mortality of a non-target

241 terrestrial insect when exposed to ULV insecticides for mosquito management is largely

242 determined by aspects of the insect's position with respect to the insecticide aerosol. Acute

243 mortality was extremely low when the front of the cages (perpendicular to the direction of the

244 insecticide droplets) was covered with plastic wrap and therefore was blocking the insecticide

245 droplets from passing through the cages (Fig. 4), even though droplets were moving past the

246 cages and the back of the cages were not covered with plastic wrap (Table 1). Therefore, the individuals were prevented from directly intercepting the droplets as they moved from the front

to the back of the cage and their mortality was much lower than the mortality in the corresponding uncovered cage.

(Figs. 5, 6). This was more pronounced in 2011 compared to 2015. This may be because cages were placed upright on the ground in 2011 compared to 2015 where cages were attached to the lower arm of the cage stand. However, the difference in height was only $6 \mathrm{~cm}$.

By adding rotary slide impingers at ground-level and $1.5 \mathrm{~m}$ at approximately the same density and volume median diameter between heights could explain the differences in mortality we observed in 2011. However, droplet density and VMD were not different between groundlevel and $1.5 \mathrm{~m}$. This suggests that there may be another factor or factors contributing to lower acute mortality of individuals at ground-level compared with individuals at $1.5 \mathrm{~m}$. As discussed above, the acute mortality of individuals in the cages at ground-level was more dependent on

261 wind speed, relative humidity, and temperature than individuals in the cages at $1.5 \mathrm{~m}$. Therefore, 
262 these environmental factors may be interacting with the insecticide droplets in as yet unknown

263 ways to influence mortality.

264 The results from this study indicate that acute mortality of adult $H$. convergens is

265 significantly determined by both the insect's ability to directly intercept the insecticide droplets

266 and its height during the spray application. More broadly, our results suggest that mortality to

267 non-target insects may vary considerably based on the ability of the droplets to impinge on the

268 insects because of something blocking the droplets and the height of the insects as the aerosol

269 passes through the area being sprayed. This is not particularly surprising because the technology

270 of using ULV insecticides for mosquito management was developed to target flying adult

271 mosquitoes and to not target insects on foliage and other landscape features (Lofgren et al. 1973;

272 Mount 1998; Mount et al. 1996). The insecticides stay aloft and a relatively low percentage of

273 what is applied settles on surfaces such as leaves and soil in the treatment area (Fisher et al.

274 2015; Hiscox et al. 2006; Preftakes et al. 2011; Schleier III et al. 2012; Tietze et al. 1994).

275 Our results may provide an explanation for why other studies generally have observed

276 low levels of non-target insect mortality from applications of ULV insecticides for mosquito

277 management. In field bioassays in which cages were placed on the ground, Schleier and Peterson

278 (2010b) did not observe significant differences in mortality of house crickets, Acheta domesticus

279 (L.), between control and treated areas for either full-labeled rates of permethrin (Permanone ${ }^{\circledR}$

280 10EC) or naled (Trumpet ${ }^{\circledR}$ EC). However, ground-based ULV applications of malathion were

281 shown to have a significant effect on house crickets when caged on the ground, causing $12.5-$

$28248.7 \%$ acute mortality, depending on their location in residential yards (Tietze et al. 1996).

283 House crickets are more sensitive than some other smaller non-target insects to pyrethroid

284 insecticides (Antwi \& Peterson 2009). 
Jensen et al. (1999) showed that the use of ground-applied ULV permethrin, pyrethrins,

286

287

288

289

290

291

292

293

294

295

296

297

298

299

300

301

302

303

304 305

and malathion above wetlands had a significant effect on night-flying insects, but abundance

recovered 48 hours after application. Davis and Peterson (2008) found no effect on terrestrial

invertebrates after single and multiple ULV applications of permethrin or $\delta$-phenothrin by ground-based equipment. After airplane-based ULV applications of pyrethrins, Boyce et al.

(2007) and Kwan et al. (2009) found no significant effect on large- or medium-bodied insects within the spray zone, but they observed an effect on small-bodied insects such as ants and chironomid midges. Kwan et al. (2009) chose sampling sites to increase the likelihood of detecting effects on non-target insects. These sites were away from significant vegetation canopy and other topographical protective elements in the treatment area that likely provided refugia for insect populations.

After aerial ULV applications of naled in which mosquitoes and Culicoides spp. biting midges were greatly reduced in number, Breidenbaugh and de Szalay (2010) observed no statistically significant reductions in numbers or diversities of most common taxa of non-target insects, except for four dipteran families. Breidenbaugh and de Szalay (2010) suggested that the reductions in numbers for the four dipteran families may have been because the insecticide was applied 2 hours before sunset and individuals in those families may have directly intercepted the aerosol cloud. Chaskopoulou et al. (2014) did not observe any deleterious effects on honey bees, Apis mellifera L., lady beetles, Cryptolaemus montrouzieri Mulsant, or green lacewings,

Chrysoperla carnea (Stephens) after aerial ULV applications of deltamethrin and $\delta$-phenothrin for adult mosquito management.

A few researchers have investigated the sensitivity of butterfly species to aerial applications of ULV mosquito adulticides. Bargar (2012b) and Bargar (2012a) suggested as part 
308 of a risk assessment that exposures to the insecticide naled for butterflies in the Florida Keys

309 would exceed levels known to cause mortality. However, the assessment assumed deposition of

310 naled droplets on surfaces would equate to direct exposure of droplets on butterflies. Neither the

311 role of position of the butterfly with respect to the aerosol cloud nor protection from interception

312 of droplets was considered. Similar assumptions and conclusions about butterfly risk have been

313 reported by Zhong et al. (2010), Hoang et al. (2011), and Hoang and Rand (2015).

314 Studies conducted to date on the effect of mosquito adulticides on non-target insects

315 indicate that there have been equivocal results. Based on our results in the present study, this

316 may be, in part, due to variability in whether the insects directly intercepted the ULV insecticide

317 droplets. Not only may insects close to the ground have reduced mortality, but insects on plants

318 and other structures in the landscape not directly intercepting the aerosol cloud, such as those

319 behind rocks, leaves, and bark, may be unaffected or experience low mortality.

320 This is further supported by several studies with honey bees. These studies suggest that

321 when the bees are inside of the hive boxes at the time of the insecticide application, as is typical,

322 there can be low mortality. Caron (1979) exposed caged honey bees and hives to ground

323 applications of ULV malathion, naled, and pyrethrum. Caged bees experienced significant

324 mortality for all treatments, but the mortality decreased rapidly with increasing distance from the

325 point of application. Exposure to hives revealed that night applications had no effect on colonies,

326 whereas day applications of malathion caused significant mortality as indicated by dead bee

327 traps. Hester et al. (2001) observed significant bee mortality within $15 \mathrm{~m}$ of the spray source in

328 hives that were exposed to four ground applications of ULV malathion both in open fields and in

329 a forested environment. There was no effect on hive weight or health of the colony over a

330 season. Zhong et al. (2004) and Zhong et al. (2003) observed similar results with aerially applied 
331 naled and noted that bees clustering outside of the hive (termed "bearding") were most

332 susceptible.

333 Future research is needed that involves additional experimental manipulation of droplet

334 interception by insects. We placed plastic wrap immediately in front of the tulle fabric at the

335 front face of the cage. A subsequent assessment could involve placing plastic sheets at increasing

336 distances from the front of cages to determine their effect on acute mortality. This would provide

337 more information on the role of objects interfering with the insect's ability to directly intercept

338 the insecticide droplets. Because droplet density and VMD did not explain differences in

339 mortality between individuals in ground-level cages compared to individuals at $1.5 \mathrm{~m}$, additional

340 research is needed that characterizes the environmental factors that affect mortality of insects at

341 ground-level. In addition, because we and other researchers have only characterized acute

342 mortality, sublethal effects could be considered in future research.

343 Our results demonstrate the importance of considerations of exposure that go well beyond

344 deposition of ULV insecticides on surfaces and extrapolation of that deposition to risk to non-

345 target insects. Insecticides currently used as outdoor space sprays for adult mosquito

346 management are broad-spectrum and highly toxic to many insects. However, ULV technology

347 most likely mitigates exposures to most insects because of small droplet sizes, extremely low

348 application rates, and application timing. Therefore, the exposure component of risk is very

349 important to understand when assessing risk to non-target insects and other arthropods. 


\section{Acknowledgements}

352 We thank those who provided field and technical support in addition to products used

353 during the study: A. Corrêa Varella, J. Callison-Bliss, Adapco, Bayer Crop Science, and Univar

354 USA, Inc. We also thank M. Flikkema and R. Brekke (MSU BART Farm) for allowing the use

355 of land for these experiments. This research was supported in part by the Montana Agricultural

356 Experiment Station and Montana State University. 


\section{Figure Captions}

358 Figure 1. Site layouts for the 2011 and 2015 experiments. Solid black circles are sample

359 locations. Red lines at $40 \mathrm{~m}$ sample location indicate blow-up of sample locations. Each sample

360 location per year would include the same information as that at $40 \mathrm{~m}$. Black "T" or "I" symbols

361 are cage stands (Fig. 3). Solid green circle is cage with front face covered in plastic wrap (Fig.

362 4). Open green circle is cage with mesh fabric face (Fig. 4). Symbols with blue circular arrows

363 are rotary impingers (Fig. 2).

365 Figure 2. Rotary impinger spinning with microscope slides coated with magnesium oxide. The

366 insecticide droplets impinge on the spinning slides, which are then quantified using a microscope

367 and software.

368

369 Figure 3. Cage stand with ground-level and 1.5-m high cages.

370

371 Figure 4. Covered cage with plastic polyvinyl chloride wrap over the tulle fabric on the front

372 (left) and uncovered cage with tulle fabric on the front and back (right).

373

374 Figure 5. Results from 2011. Cage position was highly significant $(\mathrm{P}<0.0001)$. Error bars are

375 not shown because the data are non-parametric. Mortality was significantly lower at ground level $376($ mean $=3.2 \%$, median $=0 \%)$ compared to $1.5 \mathrm{~m}($ mean $=85.2 \%$, median $=100 \%)$.

378 Figure 6. Results from 2015. Cage position and cage type were highly significant $(\mathrm{P}<0.0001)$.

379 Error bars are not shown because the data are non-parametric. Mortality by cage position and 
380 cage type was as follows: ground level, covered cage $($ mean $=2.8 \%$, median $=0.1 \%)$; ground

381 level, uncovered cage $($ mean $=41.9 \%$, median $=9.6 \%) ; 1.5 \mathrm{~m}$, covered cage $($ mean $=6.8 \%$,

382 median $=0 \%) ; 1.5 \mathrm{~m}$, uncovered cage $($ mean $=83.7 \%$, median $=100 \%)$. 


\section{References}

384

385

386

387

388

389

390

391

392

393

394

395

396

397

398

399

400

401

402

403

404

405

406

407

408

409

410

411

412

413

414

415

416

417

418

419

420

421

422

423

424

425
Abbott WS. 1925. A method of computing the effectiveness of an insecticide. Journal of Economic Entomology 18:265-267.

Antwi FB, and Peterson RKD. 2009. Toxicity to non-target insects after exposure to $\delta$ phenothrin and resmethrin. Pest Management Science 65:300-305.

ASAE. 2009. Procedure for measuring drift deposits from ground, orchard, and aerial sprayers. St. Joseph, MI: American Society of Agricultural and Biological Engineers. p 3.

Bargar TA. 2012a. The relationship between total cholinesterase activity and mortality in four butterfly species. Environmental Toxicology and Chemistry 31:2124-2129.

Bargar TA. 2012b. Risk assessment for adult butterflies exposed to the mosquito control pesticide naled. Environmental Toxicology and Chemistry 31:885-891.

Bjørnson S. 2008. Natural enemies of the convergent lady beetle, Hippodamia convergens Guérin-Méneville: their inadvertent importation and potential significance for augmentative biological control. Biological Control 44:305-311.

Boyce WM, Lawler SP, Schultz JM, McCauley SJ, Kimsey LS, Niemela MK, Nielsen CF, and Reisen WK. 2007. Nontarget effects of the mosquito adulticide pyrethrin applied aerially during a West Nile virus outbreak in an urban California environment. Journal of the American Mosquito Control Association 23:335-339.

Breidenbaugh MS, and de Szalay FA. 2010. Effects of aerial applications of naled on nontarget insects at Parris Island, South Carolina. Environmental Entomology 39:591-599.

Carney RM, Husted S, Jean C, Glaser C, and Kramer V. 2008. Efficacy of aerial spraying of mosquito adulticide in reducing incidence of West Nile virus, California, 2005. Emerging Infectious Diseases 14:747-754.

Caron DM. 1979. Effects of some ULV mosquito abatement insecticides on honey bees. Journal of Economic Entomology 72:148-151.

Chaskopoulou A, Thrasyvoulou A, Goras G, Tananaki C, Latham MD, Kashefi J, Pereira RM, and Koehler PG. 2014. Nontarget effects of aerial mosquito adulticiding with waterbased unsynergized pyrethroids on honey bees and other beneficial insects in an agricultural ecosystem of north greece. Journal of Medical Entomology 51:720-724.

Davis RS, and Peterson RKD. 2008. Effects of single and multiple applications of mosquito insecticides on nontarget arthropods. Journal of the American Mosquito Control Association 24:270-280.

Davis RS, Peterson RKD, and Macedo PA. 2007. An ecological risk assessment for insecticides used in adult mosquito management. Integrated Environmental Assessment and Management 3:373-382.

Efird PK, Inman AD, Dame DA, and Meisch MV. 1991. Efficacy of various ground-applied cold aerosol adulticides against Anopheles quadrimaculatus. Journal of the American Mosquito Control Association 7:207-209.

Elnaiem D-EA, Kelley K, Wright S, Laffey R, Yoshimura G, Reed M, Goodman G, Thiemann T, Reimer L, Reisen WK, and Brown D. 2008. Impact of aerial spraying of pyrethrin insecticide on Culex pipiens and Culex tarsalis (Diptera: Culicidae) abundance and West Nile virus infection rates in an urban/suburban area of Sacramento County, California. Journal of Medical Entomology 45:751-757. 
426

427

428

429

430

431

432

433

434

435

436

437

438

439

440

441

442

443

444

445

446

447

448

449

450

451

452

453

454

455

456

457

458

459

460

461

462

463

464

465

466

467

468

469

470

471
Fisher M, Hoel D, Farooq M, and Walker T. 2015. Deposition from ultra-low volume application of public health insecticides in a hot desert environment. Journal of the American Mosquito Control Association 31:155-163.

Fritz BK, Hoffmann WC, Farooq M, Walker T, and Bonds J. 2010. Filtration effects due to bioassay cage design and screen type. Journal of the American Mosquito Control Association 26:411-421.

Hester PG, Shaffer KR, Tietze NS, Zhong H, and Griggs Jr. J. 2001. Efficacy of ground applied ultra low volume malathion on honey bee survival and productivity in open and forest areas. Journal of the American Mosquito Control Association 17:2-7.

Hiscox AL, Miller DR, Nappo CJ, and Ross J. 2006. Dispersion of fine spray from aerial applications in stable atmospheric conditions. Transactions of the ASABE 49:1513-1520.

Hoang T, and Rand G. 2015. Mosquito control insecticides: A probabilistic ecological risk assessment on drift exposures of naled, dichlorvos (naled metabolite) and permethrin to adult butterflies. Science of the Total Environment 502:252-265.

Hoang TC, Pryor RL, Rand GM, and Frakes RA. 2011. Use of butterflies as nontarget insect test species and the acute toxicity and hazard of mosquito control insecticides. Environmental Toxicology and Chemistry 30:997-1005.

Jensen T, Lawler SP, and Dritz DA. 1999. Effects of ultra-low volume pyrethrin, malathion, and permethrin on nontarget invertebrates, sentinel mosquitoes, and mosquitofish in seasonally impounded wetlands. Journal of the American Mosquito Control Association 15:330-338.

Kwan JA, Novak MG, Hyles TS, and Niemela MK. 2009. Mortality of nontarget arthropods from an aerial application of pyrethrins. Journal of the American Mosquito Control Association 25:218-220.

Lofgren CS, Anthony DW, and Mount GA. 1973. Size of aerosol droplets impinging on mosquitoes as determined with a scanning electron microscope. Journal of Economic Entomology 66:1085-1088.

Macedo PA, Schleier III JJ, Reed M, Kelley K, Goodman GW, Brown DA, and Peterson RKD. 2010. Evaluation of efficacy and human health risk of aerial ultra-low volume applications of pyrethrins and piperonyl butoxide for adult mosquito management in response to West Nile virus activity in Sacramento County, California. Journal of the American Mosquito Control Association 26:57-66.

Mount GA. 1998. A critical review of ultra low-volume aerosols of insecticide applied with vehicle mounted generators for adult mosquito control. Journal of the American Mosquito Control Association 14:305-334.

Mount GA, Biery TL, and Haile DG. 1996. A review of ultralow-volume aerial sprays of insecticide for mosquito control. Journal of the American Mosquito Control Association 12:601-618.

Preftakes CJ, Schleier III JJ, and Peterson RKD. 2011. Bystander exposure to ultra-low-volume insecticide applications used for adult mosquito management. International Journal of Environmental Research and Public Health 8:2142-2152.

Roche JP. 2002. Print media coverage of risk-risk tradeoffs associated with West Nile encephalitis and pesticide spraying. Journal of Urban Health: Bulletin of the New York Academy of Medicine 79:482-490.

Ruktanonchai DJ, Stonecipher S, Lindsey N, McAllister J, Pillai SK, Horiuchi K, Delorey M, Biggerstaff BJ, Sidwa T, Zoretic J, Nasci R, Fischer M, and Hills SL. 2014. Effect of 
472

473

474

475

476

477

478

479

480

481

482

483

484

485

486

487

488

489

490

491

492

493

494

495

496

497

498

499

500

501

502

503

504

505

506

507

508

509

510

511

aerial insecticide spraying on West Nile virus disease-North-Central Texas, 2012. American Journal of Tropical Medicine and Hygiene 91:240-245.

Schleier III JJ, and Peterson RKD. 2010a. Deposition and air concentrations of permethrin and naled used for adult mosquito management. Archives of Environmental Contamination and Toxicology 58:105-111.

Schleier III JJ, and Peterson RKD. 2010b. Toxicity and risk of permethrin and naled to nontarget insects after adult mosquito management. Ecotoxicology 16:1140-1146.

Schleier III JJ, Peterson RKD, Irvine KM, Marshall LM, Weaver DK, and Preftakes CJ. 2012. Environmental fate model for ultra-low-volume insecticide applications used for adult mosquito management. Science of the Total Environment 438:72-79.

Schleier JJ, Preftakes C, and Peterson RKD. 2010. The effect of fluorescent tracers on droplet spectrum, viscosity, and density of pesticide formulations. Journal of Environmental Science and Health Part B-Pesticides Food Contaminants and Agricultural Wastes 45:621-625.

Sokal RR, and Rohlf FJ. 1981. Biometry. San Francisco: W. H. Freeman Co.

Thier A. 2001. Balancing the risks: vector control and pesticide use in response to emerging illness. Journal of Urban Health: Bulletin of the New York Academy of Medicine 78:372381.

Tietze NS, Hester PG, and Shaffer KR. 1994. Mass recovery of malathion in simulated open field mosquito adulticide tests. Archives of Environmental Contamination and Toxicology 26:473-477.

Tietze NS, Hester PG, Shaffer KR, and Wakefield FT. 1996. Peridomestic deposition of ultralow volume malathion applied as a mosquito adulticide. Bulletin of Environmental Contamination and Toxicology 56:210-218.

WHO. 2003. Space spray application of insecticides for vector and public health pest control: a practitioner's guide. In: Organization WH, editor. Geneva, Switzerland: World Health Organization.

Zhong H, Hribar LJ, Daniels JC, Feken MA, Brock C, and Trager MD. 2010. Aerial ultra-lowvolume application of naled: impact on nontarget imperiled butterfly larvae (Cyclargus thomasi bethunebakeri) and efficacy against adult mosquitoes (Aedes taeniorhynchus). Environmental Entomology 39:1961-1972.

Zhong HE, Latham M, Hester PG, Frommer RL, and Brock C. 2003. Impact of naled on honey bee survival and productivity: aerial ULV application using a flat fan nozzle system. Archives of Environmental Contamination and Toxicology 45:216-220.

Zhong HE, Latham M, Payne S, and Brock C. 2004. Minimizing the impact of the mosquito adulticide naled on honey bees, Apis mellifera (Hymenoptera: Apidae): aerial ultra-lowvolume application using a high pressure nozzle system. Journal of Economic Entomology 97:1-7. 


\section{Table $\mathbf{1}$ (on next page)}

Statistical relationships between cage height, distance, volume median diameter, and droplet density

Results from Wilcoxon rank sum test of volume median diameter (VMD) and droplet density. A P-value $<0.05$ indicates that distributions differ between independent variables (Groundlevel and $1.5 \mathrm{~m}$, and 20 and $40 \mathrm{~m}$ ) for each dependent variable (VMD, and Droplets $/ \mathrm{mm}^{2}$ ) 
1

2 Table 1. Results from Wilcoxon rank sum test of volume median diameter (VMD) and droplet

3 density. A P-value $<0.05$ indicates that distributions differ between independent variables

4 (Ground-level and $1.5 \mathrm{~m}$, and 20 and $40 \mathrm{~m}$ ) for each dependent variable (VMD, and

5 Droplets $\left./ \mathrm{mm}^{2}\right)$

\begin{tabular}{lrrrr}
\hline Independent Variables & \multicolumn{2}{c}{ VMD } & \multicolumn{2}{c}{ Droplets $/ \mathrm{mm}^{2}$} \\
\hline & Test Stat & P-value & Test Stat & P-value \\
Ground-level and $1.5 \mathrm{~m}$ & 1052 & 0.4858 & 808 & 0.1831 \\
20 and $40 \mathrm{~m}$ & 1192 & 0.0621 & 1264 & 0.0136
\end{tabular}

6 


\section{Figure 1 (on next page)}

Site layouts for experiments

Site layouts for the 2011 and 2015 experiments. Solid black circles are sample locations. Red lines at $40 \mathrm{~m}$ sample location indicate blow-up of sample locations. Each sample location per year would include the same information as that at $40 \mathrm{~m}$. Black " $\mathrm{T}$ " or "I" symbols are cage stands (Fig. 3). Solid green circle is cage with front face covered in plastic wrap (Fig. 4). Open green circle is cage with mesh fabric face (Fig. 4). Symbols with blue circular arrows are rotary impingers (Fig. 2). 


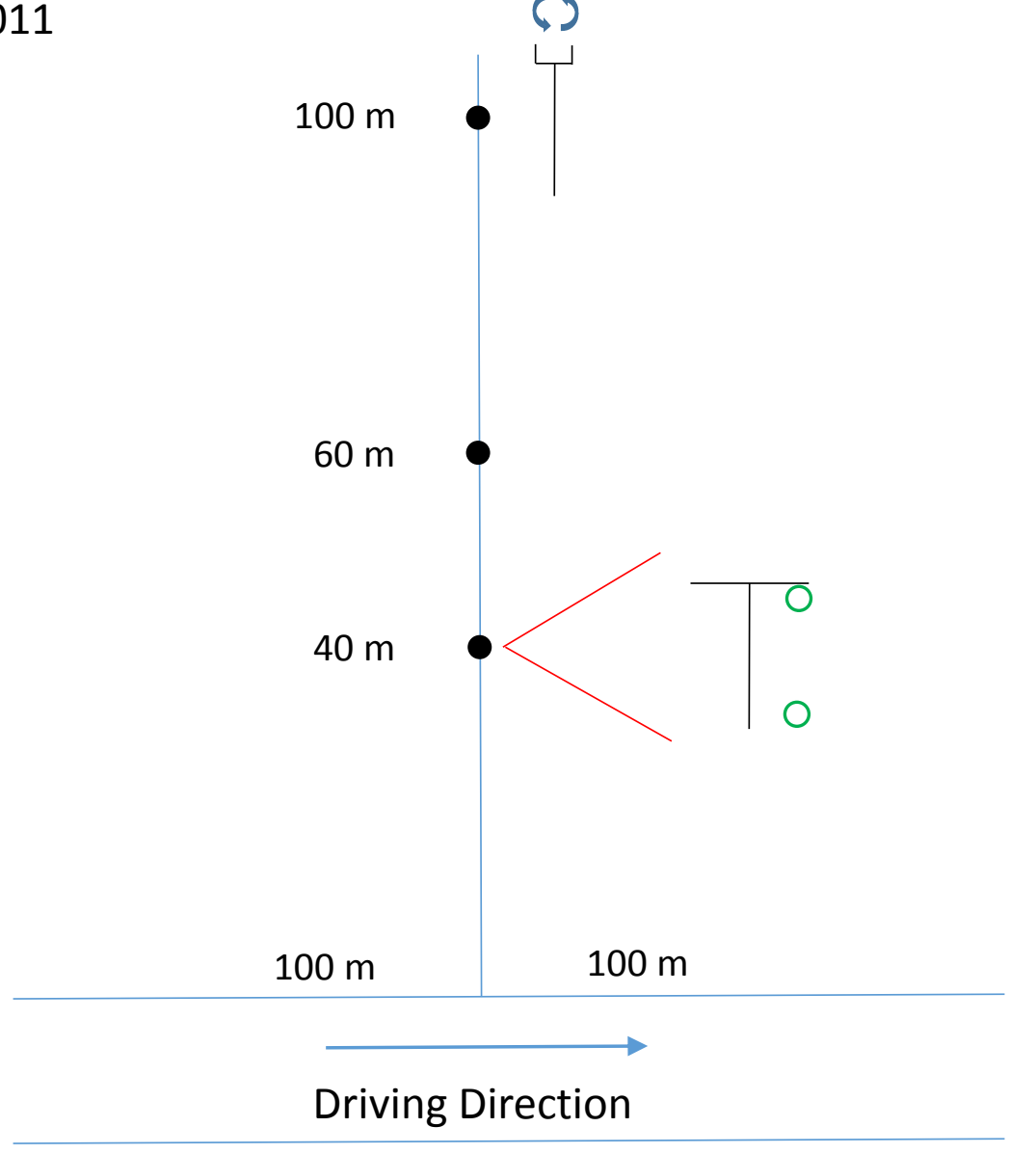

Direction

Control Site

Wind

Control Site

Wind
Direction

Driving Direction

Direction 
2

Rotary droplet impinger

Rotary impinger spinning with microscope slides coated with magnesium oxide. The insecticide droplets impinge on the spinning slides, which are then quantified using a microscope and software.

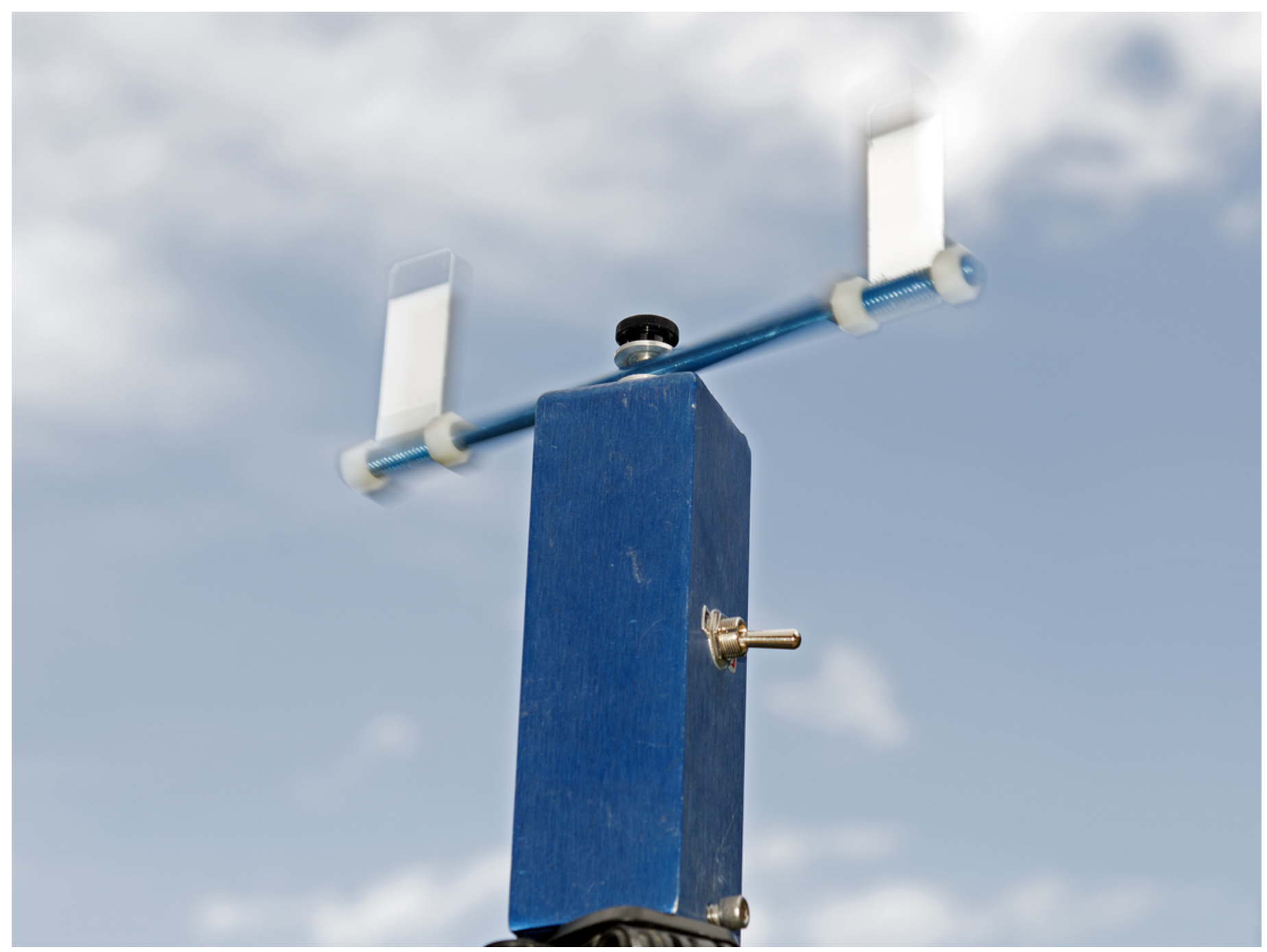


3

Cage stand with cages

Cage stand with ground-level and 1.5-m high cages. 


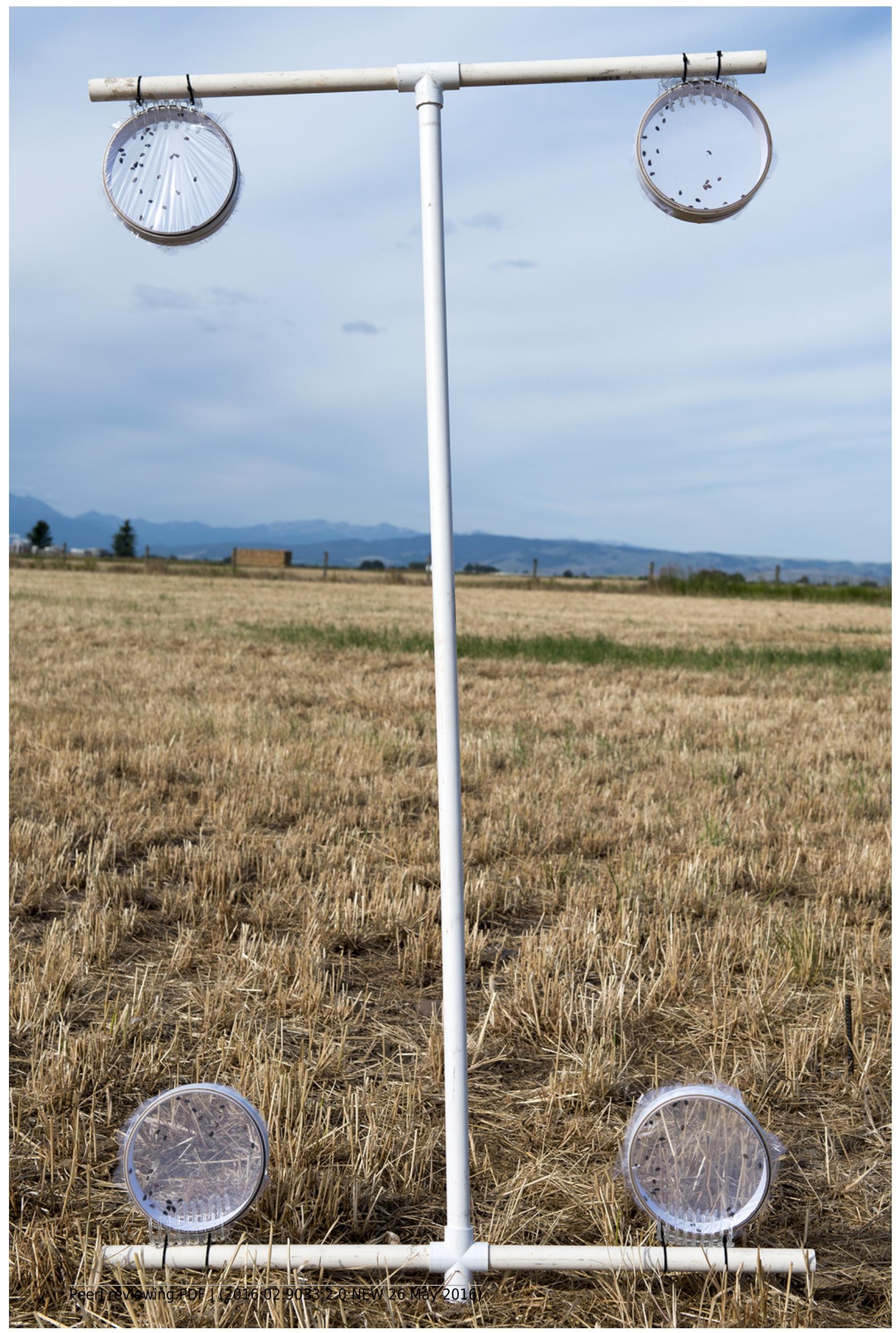


Figure 4 (on next page)

Covered and uncovered cages

Covered cage with plastic polyvinyl chloride wrap over the tulle fabric on the front (left) and uncovered cage with tulle fabric on the front and back (right). 


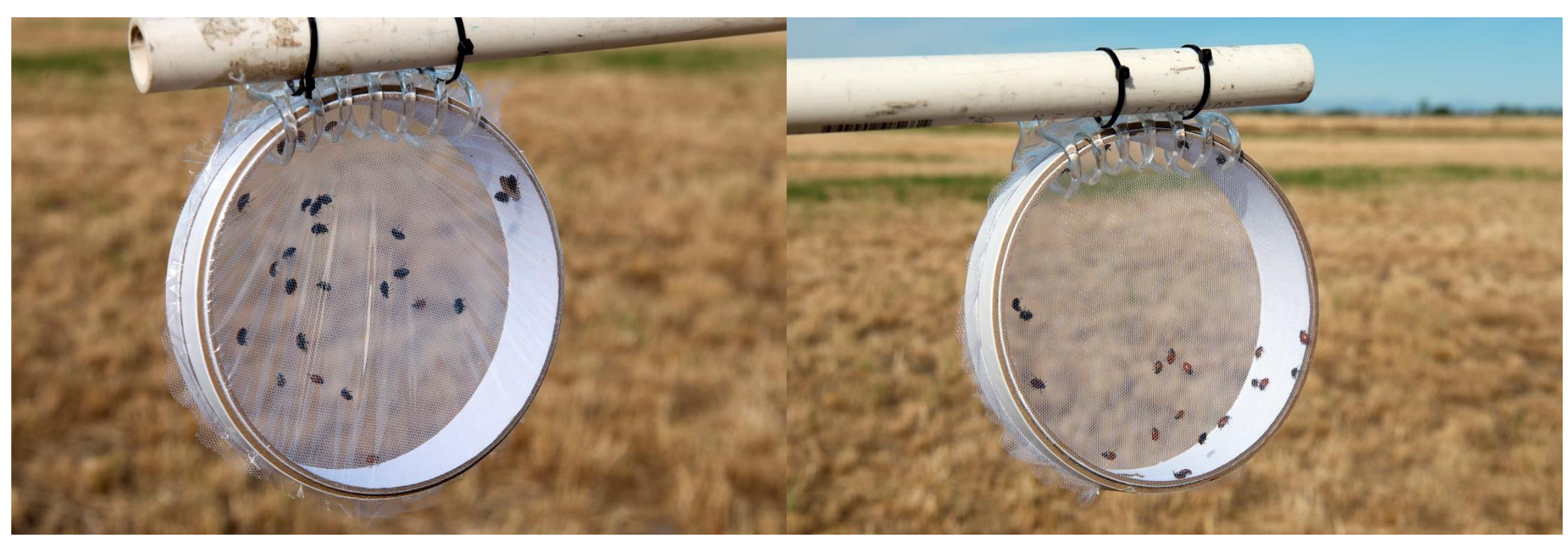


Figure 5 (on next page)

Results from 2011

Results from 2011. Cage position was highly significant $(P<0.0001)$. Error bars are not shown because the data are non-parametric. Mortality was significantly lower at ground level $($ mean $=3.2 \%$, median $=0 \%)$ compared to $1.5 \mathrm{~m}($ mean $=85.2 \%$, median $=100 \%)$. 


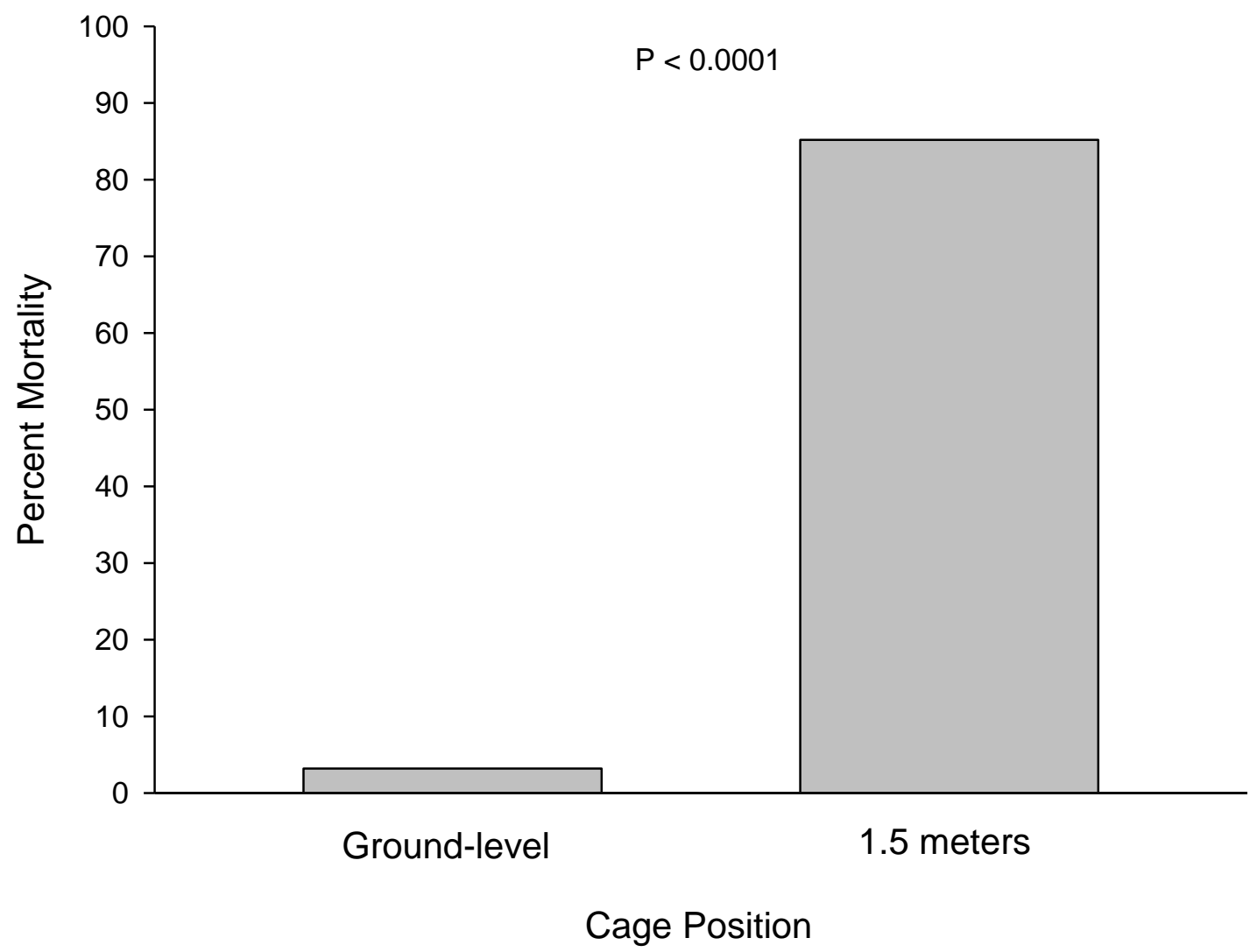




\section{Figure 6 (on next page)}

\section{Results from 2015}

Results from 2015. Cage position and cage type were highly significant $(P<0.0001)$. Error bars are not shown because the data are non-parametric. Mortality by cage position and cage type was as follows: ground level, covered cage ( mean $=2.8 \%$, median $=0.1 \%$ ); ground level, uncovered cage (mean $=41.9 \%$, median $=9.6 \%) ; 1.5 \mathrm{~m}$, covered cage (mean $=6.8 \%$, median $=0 \%) ; 1.5 \mathrm{~m}$, uncovered cage $($ mean $=83.7 \%$, median $=100 \%)$. 


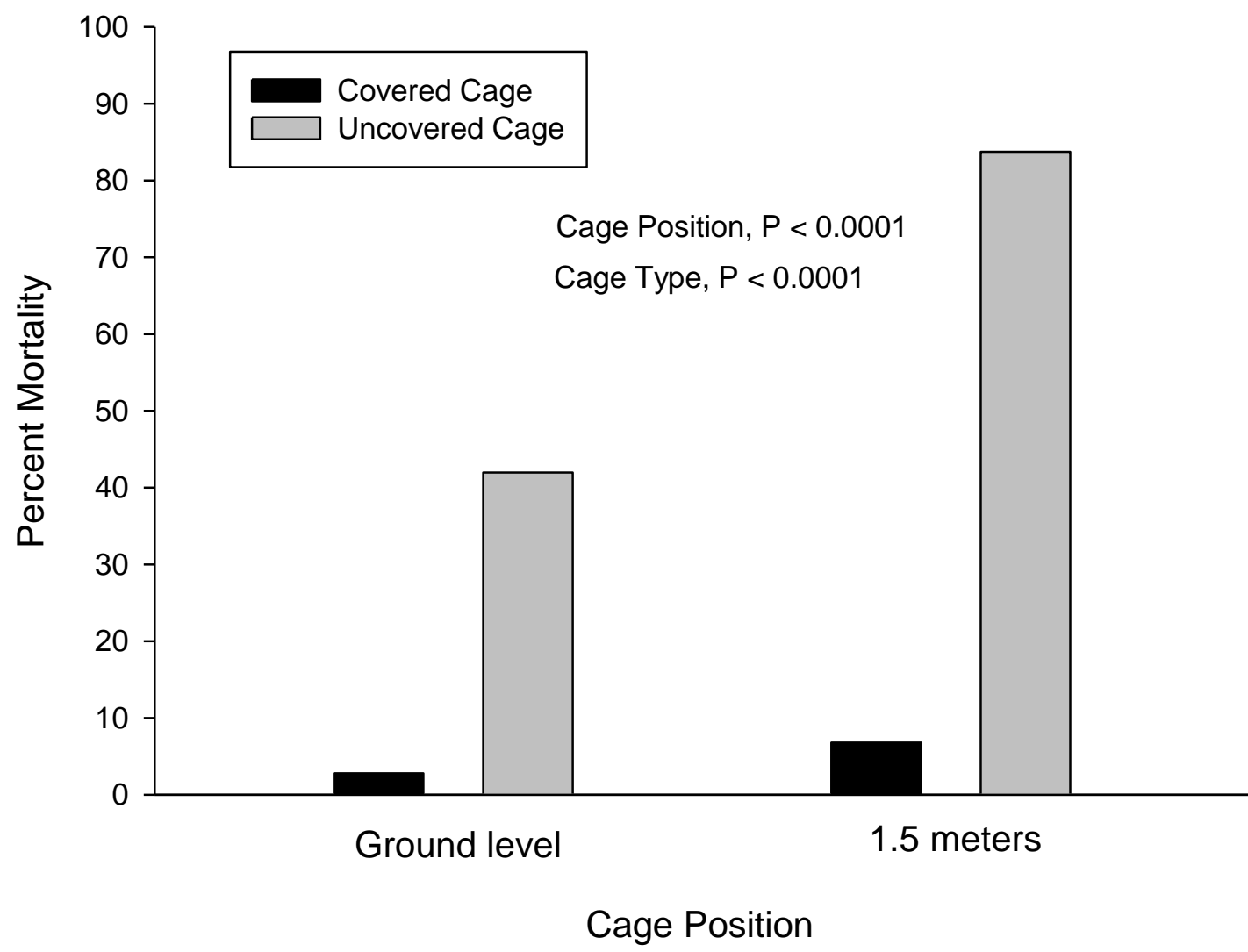

